\title{
The effects of age, weight and experience on relative sugar preference in the albino rat'
}

\author{
Mahlon W. Wagner 2 \\ UNIVERSITY OF MASSACHUSETTS
}

\begin{abstract}
This study examined the effects of weight, age and experience on relative sugar preference and satiation. Albino rats were given $6 \mathrm{hr}$. per day of free choice between a $12-1 / 2 \%$ and a $25 \%$ glucose solution for 14 days. The three groups were given this experience at ages 8 weeks, 12 weeks and 16 weeks.

Although body weight significantly affected absolute intake of sugar solutions, age alone produced no differences in preference or differential effects from experience. For all groups the 14 day period served to clarify their preference as the animals ingested progressively more of the $25 \%$ glucose solution and correspondingly less of the $12-1 / 2 \%$ solution.
\end{abstract}

\section{Introduetion}

Young (1959) has pointed out that preferential food habits are definitely acquired and result from practice and further, that food habits, once formed, tend to persist even when the selections are out of line with metabolic needs.

Investigating the effects of experience on relative sugar preference, Jacobs (1958) used injections of insulin to cause a specific hunger for glucose in rats. Under normal dietary conditions rats preferred a $10 \%$ glucose solution to a $35 \%$ solution, but the introduction of insulin resulted in a shift to the $35 \%$ solution. $\mathrm{He}$ found that additional experience with the $10 \%$ glucose solution prior to the insulin administration inhibited the shift in preference to the sweeter solution to the extent that the animal would merely ingest greater amounts of the more palatable $10 \%$ solution.

Harriman (1955) gave extended experience in order to establish a strong sugar-over-salt preference in normal rats. After undergoing an adrenalectomy these rats did not develop the usual post-operative preference for salt (Richter, 1936) with the result that four of the 20 rats died and the others lost weight. Harriman concluded, as does Young, that previous experience can interfere with the development of a subsequent appetite when a dietary need arises.

To the present time most research has been directed toward food preference as affected by experience interacting with the physiological needs of the animal. However, there have been very few behavioral studies on shifts in preference simply as a function of age and experience without the intervention of induced metabolic needs. This study is a direct extension of the author's thesis research (1963) and deals with the effects of age, weight, and experience as dimensions that affect the relative preference of sugar solutions.

\section{Subjects}

Fourteen male albino rats of the Wistar strain born on the same day were used in this study. These rats were individually caged with an ad-libitum supply of standard laboratory food and water.

\section{Apparatus}

The two sugar solutions used were composed of $12-1 / 2 \%$ and $25 \%$ anhydrous glucose by weight. These solutions as well as water were made available to the rats by using inverted graduated cylinders with $\mathrm{J}$-shaped metal drinking tubes of approximately $3 \mathrm{~mm}$ inside diameter.

\section{Procedure}

The animals were randomly assigned to three groups of five rats each, all of which received identical treatment with the sole exception of the age when the treatment was received. One rat in Group II (age 12 weeks) died before completion of the experiment. The treatment consisted of one 6-hr. session per day for 14 days during which the rats were given a free choice between drinking the $12-1 / 2 \%$ glucose solution and the $25 \%$ solution.

The three groups were given this treatment starting at the ages of 8,12 and 16 weeks.

Measurements were taken of the amount of each solution consumed to the nearest cubic centimeter after $1 \mathrm{hr} ., 3 \mathrm{hr}$., and at the end of the 6-hr. period and converted to intake per hour.

\section{Hesults}

At the different ages of the treatment groups, the animals' weights varied markedly. The beginning and end weights for each age group were: Group I, 8 weeks old, $182 \mathrm{gm}$ and $266 \mathrm{gm}$; Group II, 12 weeks old, $308 \mathrm{gm}$ and $372 \mathrm{gm}$; and Group III, 16 weeks, $399 \mathrm{gm}$ and 444 gm. An analysis of variance on the raw data of sugar solution intake with weight, concentration of glucose, over 14 days, and the first $3 \mathrm{hr}$. vs. second $3 \mathrm{hr}$. (satiation) as the variables, showed all main effects to be significant beyond $p=.001$. The interactions of glucose concentration with satiation and glucose concentration over days were also significant at the same level. Only one interaction effect involving the weight factor (weight by concentration by days) was not significant at or beyond the $\mathrm{p}=.05$ level. Thus the animal's bodyweight was a potent factor in determining intake of the two sugar solutions. Figure 1 presents the raw data for the first hour's intake.

To offset the bias of bodyweight, the intake data were corrected to cc of liquid consumed per $\mathrm{kg}$ of bodyweight. These data for each of the two glucose 


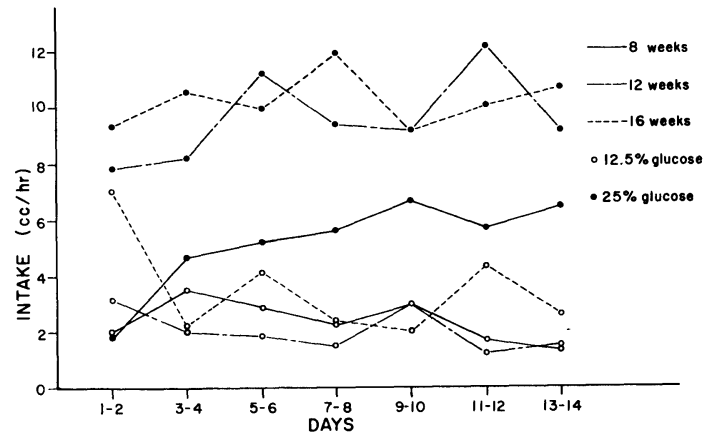

Fig. 1. The effects of age (weight) and experience on sugar preference in the first hour.

solutions consumed by all three groups over the 14day period (compressed into seven two-day periods) are presented in Fig. 2. When this correction for bodyweight is made, inspection of the data shows that there are no systematic differences between the groups due to age at which the experience was given.

The effects of the prolonged exposure to the two sugar solutions was to gradually decrease intake of the $12-1 / 2 \%$ glucose solution and simultaneously increase intake of the $25 \%$ glucose solution over the 14-day period.

Within each day's 6-hr. period the effects of satiation were to sharply reduce additional intake after the first hour. Except for Group I on day one, all groups preferred the $25 \%$ glucose solution at all times as indicated by higher rates of intake of the sweeter solution. In addition, for both solutions there is a steady, declining rate of intake over the 6-hr. period indicative of satiation.

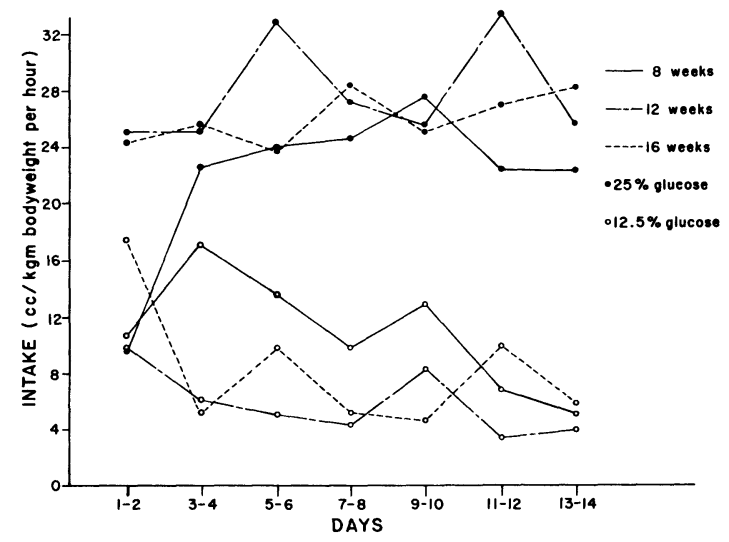

Fig. 2. The effects of age and experience on intake of sugar solutions in the first hour.

\section{Diseussion}

If the effects of bodyweight are removed, it is seen that between 8 weeks of age and 16 weeks of age there are no differences in sugar preference attributable to age alone. However, prior experience, as Young has pointed out, markedly affects sugar preference. Up to five or six days in the present study were needed to clearly distinguish a preference between the two solutions, with further experience serving primarily to decrease variability around the group means.

The effects of satiation did not alter relative preference in that rates of intake for both solutions were lowered during the last 3 to $5 \mathrm{hr}$. of a session although the $25 \%$ glucose solution remained the preferred. That is, with the two concentrations employed, sugar preference was not affected by satiation. However, rate of intake did change thereby providing a good measure of satiation during the 6-hr. period. This same satiationinduced phenomena is also reported over a 24-hr. period by Wagner (1965).

The implications for studies of food preference are that animals should have sufficient prior experience to have achieved an "asymptote" in terms of a relatively stable intake or preference before other variables are introduced in which preference changes are studied. It is also most convenient if data are expressed as rates of intake rather than cumulative intake since the latter obscures the effects of satiation which may alter relative preference over prolonged periods of testing.

\section{Referenees}

HARRIMAN, A. The effect of a pre-operative preference for sugar over salt upon compensatory salt selection by adrenalectomized rats. J. Nutrition, 1955, 57, 271-276.

JACOBS, H. L. Studies in sugar preference: I. The preference for glucose solutions and its modification by injections of insulin. J. comp. physiol. Psychol., 1958, 51, 304-309.

RICHTER, C. P. Increased salt appetite in adrenalectomized rats. Amer. J. Physiol., 1936, 115, 155-167.

WAGNER, M. W. The effects of learning and experience on sugar preference in the albino rat. Unpublished doctoral thesis, University of Rochester, 1963.

WAGNER, M. W. Satiation effects on rate of intake and preference for glucose solutions. J. comp. physiol. Psychol., 1965, 59, 115-117.

YOUNG, P. T. The role of affective processes in learning and motivation. Psychol. Rev., 1959, 66, 104-125.

Notes

1. This study was supported by research funds from the University of Massachusetts Faculty Research Fund.

2. Now at Valparaiso University. 